\title{
The 1982 Annual Meeting of the American Academy of Child Psychiatry
}

\author{
Michael H. Best, Consultant Child Psychiatrist, Bristol
}

The 29th Annual Meeting of the American Academy of Child Psychiatry was held in Washington, DC in October 1982. The proceedings were under the presidency of James Anthony, and David Shaffer was Chairperson of the Programme Committee.

The conference provided a full scientific programme as well as special events and presentations, with an emphasis on child psychiatry in the future. There were two plenary sessions; in the first Jerome Bruner spoke on 'Communication and Interaction During Development'. Later Anthony Rudel gave a talk, illustrated with musical extracts, on 'Mozart's Childhood-His Music and Letters'. The President's Panel presented 'Jean Piaget: A Celebration' in which James Anthony, William Kessen and Gilbert Voyat traced the course of Piaget's life and ideas from childhood to old age. Also, Margaret Mahler presented a film of her work.

Participants could choose from the 116 papers presented, 27 panels and 13 workshops: sessions covered problems and findings in childhood depression, biological psychiatry, training, in-patient care and the impact of traumatic experiences. The workshops emphasized such treatment skills as group therapy, family therapy, cognitive therapy and social skills training. An important feature of the programme was sessions devoted to research tools and designs.
A local Arrangements Committee planned a variety of activities including a visit to the National Institute of Mental Health, Bethseda, and a moonlight tour of Washington.

The meeting was most interesting and enjoyable in view of the wealth of clinical and research material presented. I found of special interest the attempts being made to relate epidemiological studies and behavioural check-lists to diagnostic categories used in clinical practice, research methodology for treatment assessment, and the integration of biological psychiatry and child therapy with family therapy. Also of interest was 'Project Future'-a three-year undertaking begun in 1979, the principal objective of which is to forecast new directions and priorities for the field of child psychiatry to pursue in the 1980 s. The final report is expected soon. Although there are 3,000 child psychiatrists practising in the United States, the Academy's manpower estimate of requirements is for between 8,000 and 10,000 in order, as Irving Phillips has stressed, to reach out to many children not receiving services.

This meeting clearly demonstrated how child psychiatry in America is in the hands of enthusiastic clinicians and research workers. If you have the opportunity to be in the United States around the time of the Academy's Annual Meeting, it would be well worth attending it.

\section{News Items}

\section{Squibb Scholarship in Community Psychtatric Nursing}

Applications are invited for the 1983 award of the above scholarship, donated by E. R. Squibb and Sons Ltd and organized in conjunction with the Royal College of Nursing and the Community Psychiatric Nurses' Association. The scholarship is open to all nurses primarily involved in community nursing of the mentally ill or mentally handicapped in the UK. Details of the conditions of entry and the format of the submission are available from Noel Carr, Psychiatric Hospital Manager, E. R. Squibb and Sons Ltd, Squibb House, 141-149 Staines Road, Hounslow, Middlesex TW3 3JB. Closing date for submission of entries: 31 March 1983.

\section{Workshop on 'New Theraptes'}

On 20 September 1982 a 'New Therapies' workshop took place at the British Postgraduate Medical Federation. The theme of the workshop concerned practical aspects of psychotherapy supervision. A number of difficulties in conventional psychotherapy supervision were identified, for example, the material presented to the supervisor is inevitably selective and may be biased towards pleasing the supervisor rather than presenting an objective account of what took place during treatment.

John Cobb (Senior Lecturer in Psychotherapy at St George's Hospital) guided participants through a number of exercises based on action techniques which were designed to explore material derived from real clinical situations from a different perspective. The exercises were followed by group discussion.

The workshop demonstrated that such techniques may be integrated with conventional types of supervision, particularly where the supervision is on a time-limited basis, as in the NHS. It enables the therapist not only to explore what is going on in a session, but also to recognize and report his own emotional reaction. These supervisory methods demonstrated appear to be useful within any theoretical framework ranging from behavioural to psychoanalytic.

W. FALKOWSKI 